\title{
Recent Research on Wireless Body Area Networks: A Survey
}

\author{
Sachi N. Shah \\ Department of Computer Engineering, \\ SVM Institute of technology, \\ Bharuch 392-001, Gujarat, India
}

\author{
Rutvij H. Jhaveri \\ Department of Computer Engineering, \\ SVM Institute of technology, \\ Bharuch 392-001, Gujarat, India
}

\begin{abstract}
Wireless Body Area Network (WBAN) is a kind of wireless sensor network (WSN) which can be wearable or implantable in the human body. WBAN is an emerging technology in the field of healthcare system. WBAN has received great attention due to its applications in the field of health, medical, entertainment services and many more. The main idea behind WBAN technology is to deploy them in the medical system to replace wires with the help of sensor nodes implanted into the patient's body or placed around the patient body. Not only it gives more comfort to the patient, but also patient can be treated remotely by the healthcare system staff. It is very helpful to the elderly people or people with any disability to provide medical facility at home or in any emergency condition. WBAN has been a vast area for researchers in recent years. In this Paper, we have carried out survey of various existing approaches of WBAN and describe the future scope for further research in the field. The literature survey depicts that the existing schemes can be further modified to devise more reliable solutions for WBAN schemes.
\end{abstract}

\section{Keywords}

Wireless Body Area Network, Sensor network, Healthcare, Existing Approaches

\section{INTRODUCTION}

Recent years ago medical field has no more development in its medical devices and healthcare systems. Due to its lack of facility, patients put their lives on risk in emergency condition. Medical facilities were providing with full of wires and very complex to handle it for patient. Nowadays Medical field is very developing field and Wireless body area network (WBAN) is one of the emerging technology in the field of healthcare system which is able to change the landscape of the medical systems and its way of delivery [1]. Due to its variety of applications such as medical, health, and entertainment services, WBAN has received great attention [2]. Many medical devices such as Electrocardiography (ECG), Insulin Pumps, Pacemakers, Implantable Cardioverter Defibrillators (ICD), temperature and pulse sensors, all have been also moved to WBAN technologies. WBAN technology reduces the problem of wires in the healthcare system and increases the comfort of the patient and provides ability for healthcare system to monitor patient remotely [3].

A Goal of Body area network is health-care system that guarantees the continuous, reliable gathering and objective analysis of physiological and behavioral aspects of a patient, and delivers this information to physicians. In WBAN sensor nodes are placed on the human body or placed on everyday clothing [4].

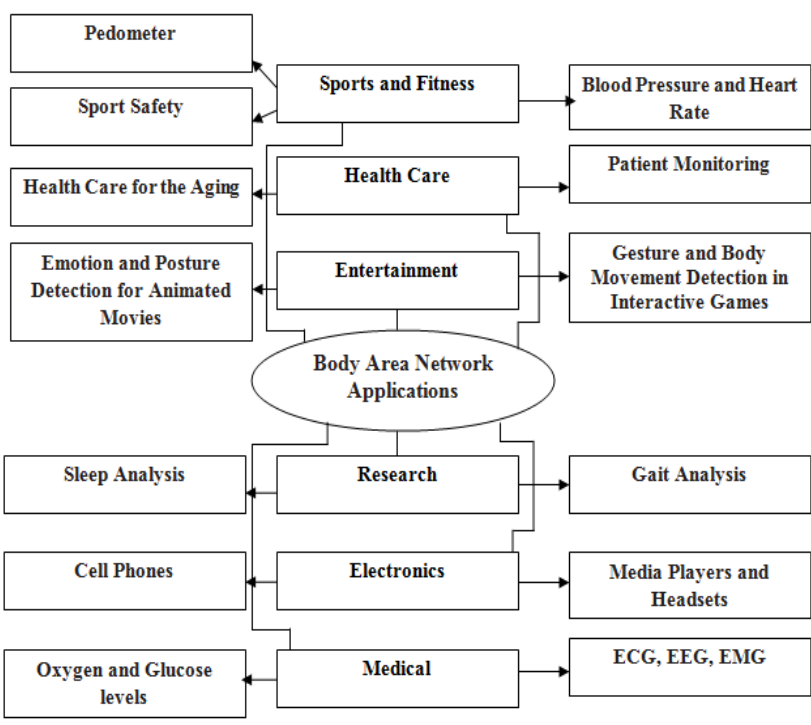

Fig.1. The applications of BANs [4].

In WBAN the benefits at one hand, there are also various issues like interference and eavesdropping that Body area network should solve on other side. Energy efficiency related issues resolve by various MAC layer techniques. Use the human body as a communication channel is more energy efficient and reliable [4].

The rest of Paper is organized as follow: In section 2 related works on various WBAN approaches is mentioned and in final section paper is concluded.

\section{RELATED WORK}

We have carried out literature survey of the various WBAN approaches which are described as follows and also explained in Table I

Lee et.al [2] presents a dual-band printed antenna with metal back-cover for WBAN applications that is in operation in 2.45 gigahertz and 5.8 gigahertz industrial, scientific, and health (ISM) groups. Analyze the performance of the proposed antenna flatbed body is used that is adore physical body.

Kim et.al [5] a MAC protocol that applies on the delay limitation to MAC Protocol in medical signal observance to scale back the time delay and packet loss in TDMA primarily based CSMA/CA surroundings. The Proposed MAC Protocol's superintendent frame has same sort and structure as Bio MAC protocol super frame. The proposed Method's aim is to decrease delay therefore it is named DTD-MAC (Decrease of Transmission Delay). In this paper WBSN surroundings is established as star and computer simulation is 
conducted in static environment within which range of node devices doesn't amendment. DTD-MAC Protocol is efficient additional than Bio-MAC.

Thamilarasu et.al [1] proposed an autonomous mobile agent primarily based intrusion detection design to deal with security in wireless body area networks. In this paper intrusion detecting in WBAN by mobile agent migration and cooperative performance. Every node in the WBAN behaves as computing node. In this paper, a multiple mobile agents based intrusion detection system is developed so, learning and decision creating is distributed among totally different nodes within network.

Froehle et.al [6] gives plan concerning analysis on WBAN for area that provides safety of future astronaut throughout area Exploration, advance health industry and technology. In the spacesuit health watching system, Bluetooth module and sensors should be enforced on the interior aspect of the pressure suit to with efficiency live important signal and to shield instrumentation from worst surroundings and antenna must be connected to the Bluetooth. In the simulation Perfect Electric Conductor (PEC) was used because the ground plane material that improves the antenna output however having air gap is downside in pressure suit therefore to decrease this gap a folded ground style was enforced.

Kim et.al [7] proposed a Multi hop WBAN construction theme that have 3 operations: (1) the clustered topology setup, (2) mobility support, (3) transmission efficiency improvement. Existing schemes work on 1-hop based star network that is helpful just for short vary network on the opposite hand multi hop network have immeasurable benefits.

He et.al [8] proposed Body topology model was made primarily based on the particular spatial distribution of the medical sensors. They used two Ad- hoc routing protocol AODV and DSDV for this model. Both of this protocol, AODV is more appropriate for transmission of knowledge below form setting.

Ramlall et.al [9] proposed a timestamp-free synchronization algorithmic rule. In this algorithm the sensors change once they transmit their messages to the central communication node. Central communication node knows the sensing element node's time offset is at intervals want level of your time accuracy and if time offset is exceeds the desire level of time accuracy at that point central communication node answer sensing element node.

Yan et.al [10] proposed a wearable dual-band magnetoelectric dipole antenna. The proposed antenna is planned for worn purpose therefore they will check antennas on body performance evaluated below bending conditions. Bending Evaluation is performed by simulating the antenna mounted on a vacuum cylinder with a varied radius $r$. This complementary antenna is capable of producing a stable performance in terms of gain, beamwidth and radiation pattern within a large operative waveband.

Al Rasyid et.al [11] presents the implementation of WBAN for monitoring body temperature, heart beat rate and oxygen saturation in blood. They analyzed the information received from sensing element nodes to server receiver with a spread of various distances.

Viittala et.al [12] Presents Routing in WBAN which are focusing on routing occurring in personal and native areas of WBAN. They used Fuzzy logic for optimal resolution which needs less procedure power than typical ways. Zone routing protocol is proposed protocol that is hybrid protocol, combination of reactive and proactive routing protocol. WBAN communication architecture will be divided into 3 communication tiers are intra-WBAN, inter-WBAN and beyond-WBAN based on the communication occur on the body.

Hämäläinen et.al [13] gives plan regarding the European level customary proposal for sensible wireless body area networks. SmartBAN concept is primarily based on the heterogeneous multi-radio approach and SmartBAN hub act as a relay or bridge between devices operative with totally different radio standards. The proposed knowledge model is divided into 3 main parts: BAN, Nodes, Process and Measurements. A SmartBAN is identified by with the facilitate of its BANID that ought to be distinctive and accessible by any licensed user. The SmartBAN is using 2 totally different channels: a control channel, a data channel. At last we could say that SmartBAN is employed for monitoring specific phenomena.

Lahlou† et.al [14] proposed on the energy optimisation issue and the joint routing and MAC protocols in WBANs. In this paper author present their antecedently style model EnergyAware Topology style for WBANs (EAWD), its weakness and extend the EAWD as Enhanced EAWD (EEAWD).EAWD is a mathematical framework supported the integer liner programming. It has two mathematical issues: the set covering and multi-commodity flow problems. Design of EEAWD framework is planned for people with low quality, like the elderly people.

Zang et.al [15] presents a new transmission power control theme, which is Motion aware transmission power control (M-TPC) theme in the dynamic WBAN state of affairs.TPC theme in WBAN area unit 3 sorts particularly real-time reactive scheme, dynamic postural position inference (DPPI) mechanism, and link-state-estimation-based transmission power control (LSE-TPC) protocol. In this paper author assume that physical activity recognition algorithm has already been applied and also the activity of walking is acknowledged effectively. The relationship between body movement and link quality is examined by the experiment.

Sangari et.al [16] presents the proposed scheme comprises 3 section: (1) Data acquisition phase, it performs monitoring and transferring the patient data.(2) Data transfer section, it performs transmitting the signals between the sensors and Hospital network. (3) Data access section, it performs accessing and monitoring the patient data. This proposed technique is combination of each symmetric and asymmetric cryptography mechanism. For transmission security of biomedical system authors use RC6 block cipher that is derived from RC5.

Ambigavathi et.al [17] proposed a Priority Queuing formula with using AODV protocol to differentiate varied sorts of data traffic supported vital data. Simulation result performs comparison between traditional AODV while not priority and planned AODV with priority. In traditional AODV traditional FIFO planning formula is used that is typically making drawback for emergency case. In proposed AODV this drawback is solve with the facilitate of pre-emption and Non pre-emption condition.

Nhan Le et.al [18] proposed a new theme Asynchronous Wake-up on Demand MAC protocol (AWD-MAC) supported the Receiver Initiated Cycled Receiver (RICER) protocol using nano-watt wake up radio (WUR) in star topology. Wake up radio is ultra low power hardware that receives 
awaken signals within the type of data or commands. The proposed protocol has 2 sections: the neighbor discovery section and the asynchronous communication phase.

Pereira et.al [19] proposed a complementary solution for blind individuals. Authors proposed ultrasound detector based mostly body area network for obstacle detection for blind individuals once they area unit moving from one place to a different and not using white or Seeing Eye dog. The ultrasound sensor manufacture sound as feedback once observe obstacle. To detect obstacles authors projected 2 modules: (1) The jacket module (2) The elastic bands.

Youssef et.al [20] proposed for firefighters as a firefighting theme primarily based on WBAN system. A cluster-based hierarchical topology is designed and a cooperative communication model is planned for permitting firefighters to work in teams and planned 2 new models particularly, cellular automata and wave propagation models. Three types of actor presents within the system are the firefighter, the team leader and the incident commander. To increase the accuracy of collected data and reduce the speed of false positive WBAN sensors are distributed in 5 circles.

Wang et.al [21] proposed associate degree inter-wireless body area network programming rule for animal health observance. Which is performs in 2 steps due to combinable quality improvement problem. Step 1 is Transmit Parameters Determination in that 3 phases. Step 2 is Time Slot Allocation within which also 3 phases.

Gambhir et.al [22] show the problem of congestion management in transport layer and for its resolution the planned methodology work on 2 congestion management rule of transmission control protocol (TCP) are: slow begin and congestion rejection rule. Four factors affecting on the congestion of transport layer are: Queue length, Packet loss, Bandwidth, Delay and the proposed methodology work on 2 of them queue length with packet loss. Proposed methodology has 2 main phases: fast begin and Congestion management module.

Chevalier et.al [23] studied the feasibility of optical WBAN. Wireless optical communication (WOC) is complement for Radio frequency in indoor WBAN system. In indoor WBAN system there are 2 sort of transmission state of affairs on the market. One is on-body communication and second is extrabody communication. For proposed approach author took on body communication and NON-Line of sight propagation, which exploits the diffuse optical reflections over the surroundings.

Pathak et.al [24] presents the energy optimization in the beacon enabled mode of IEEE 802.15.4 in that all-mains duty cycle operation is achieved by setting 2 system parameters, macBeaconOrder (BO) and macSuperframe order (SO). IEEE 802.15.4 consists of 2 sorts of devices which might be FFDs (full function devices) and RFDs (reduced function devices). IEEE 802.15.4 supported 3 kind of network topology: the star, mesh and tree topology.

Zhao et.al [25] presents an identity (ID)-based economical anonymous authentication theme for WBANs using elliptic curve cryptosystem (ECC). It has three sections: initialization phase, the registration section and the authentication phase. The proposed approach is providing varied security properties with attacks.

Rahman et.al [3] Propose mainly 2 section, In the first section, the security of WBAN system are assess by using Pratical
Impact Assessment (PIA).The PIA measure WBAN security threats primarily based on 3 parameters are Confidentiality, Integrity and availability. In the Second phase, using Inputs from PIA, develop forensics readiness architecture for WBAN. This architecture for WBAN can facilitate prevent WBAN security threats and realize out the attacker if attack is occur. The set of four wireless security threat selected for PIAm are Eavesdropping, Denial of Service (DoS), Authentication Bypass, Role Bypass.

Ansari et.al [26] gives data regarding RF and non-RF primarily based communication techniques will be used for WBAN. Human body communications (HBC) technique is predicated on non-RF based technique.HBC can perform 2 methods: capacitive coupling, galvanic coupling. In Capacitive coupling single electrode is used at the each transmitter and receiver side and alternative electrode remains floating. In galvanic coupling pair of electrode is used at each transmitter and receiver side. Also provides comparison between HBC and RF and Application of HBC.

Sipal et.al [27] Present study on 3 hub locations in WBANs for fitness situations. Three WBAN design are a waist-centric; a head-centric network and a footwear centric network. For each hub position, four positions of WBAN nodes introduced are chest; back; left and right higher arm. The transfer functions of the wireless channel, H(f) between the hubs and individual nodes are analyze and recorded for 2 sets of exercises are push-up exercise and squat exercise. For each exercise measure was taken and measure was recurrent for 2 test specifically male and feminine. Another approach is study in this paper is cumulative distribution function (CDF).

Dautov et.al [28] proposed a light-weight cryptography framework for augmenting Compressed Sensing (CS) with Wireless Physical Layer Security (WPLS). It defines four principal components particularly Secret Bits Distillation, LFSR, Sensing Matrix Generation, and CS Encryption. In the proposed theme no would like for separate cryptography algorithmic program. Authors evaluate the performance of the planned framework on real world ElectroCardioGram (ECG).

\section{CONCLUSION}

WBAN is an emerging technology in field of medical and provides comfort to human and makes work easy for medical staff. In this survey paper, we have carried out survey of various existing approaches for WBAN. We studied various mechanisms based upon MAC layer, physical layer, and transport layer along with various security mechanisms. WBAN has vast number of applications and based on the application various mechanisms are devised to optimize its performance. Each of the proposed mechanisms performs well under specific scenarios and assumptions, but each has its own limitations. Therefore, we can conclude that no mechanism performs exceptionally well in all scenarios, but it proves to be exceptional in certain environments.

\section{REFERENCES}

[1] Thamilarasu, Geethapriya, and Zhiyuan Ma. "Autonomous mobile agent based intrusion detection framework in wireless body area networks." In World of Wireless, Mobile and Multimedia Networks (WoWMoM), 2015 IEEE 16th International Symposium on a, pp. 1-3. IEEE, 2015.

[2] Lee, Wonseok, and Jaehoon Choi. "A dual-band printed antenna with metal back-cover for WBAN applications." In Antennas and Propagation \& USNC/URSI National 
Radio Science Meeting, 2015 IEEE International Symposium on, pp. 936-937. IEEE, 2015.

[3] Rahman, Abdul Fuad Abdul, Rabiah Ahmad, and Sofia Najwa Ramli. "Forensics readiness for wireless body area network (WBAN) system." In Advanced Communication Technology (ICACT), 2014 16th International Conference on, pp. 177-180. IEEE, 2014.

[4] Johny, Blessy, and Alagan Anpalagan. "Body area sensor networks: Requirements, operations, and challenges." Potentials, IEEE 33, no. 2 (2014): 21-25.

[5] Kim, Rae Hyun, Pyung Soo Kim, and Jeong Gon Kim. "An effect of delay reduced MAC protocol for WBAN based medical signal monitoring." In Communications, Computers and Signal Processing (PACRIM), 2015 IEEE Pacific Rim Conference on, pp. 434-437. IEEE, 2015.

[6] Froehle, Patrick, Tyler Przybylski, Christopher McDonald, Milad Mirzaee, Sima Noghanian, and Reza Fazel-Rezai. "Flexible Antenna for Wireless Body Area Network." In Antennas and Propagation \& USNC/URSI National Radio Science Meeting, 2015 IEEE International Symposium on, pp. 1214-1215. IEEE, 2015.

[7] Kim, Tae-Yoon, Sungkwan Youm, Jai-Jin Jung, and EuiJik Kim. "Multi-Hop WBAN Construction for Healthcare IoT Systems." In Platform Technology and Service (PlatCon), 2015 International Conference on, pp. 27-28. IEEE, 2015.

[8] He, Pengfei, Xiao Li, Long Yan, Shan Yang, and Boye Zhang. "Performance analysis of wban based on aodv and dsdv routing protocols." In Future Information and Communication Technologies for Ubiquitous HealthCare (Ubi-HealthTech), 2015 2nd International Symposium on, pp. 1-4. IEEE, 2015.

[9] Ramlall, Rohan. "Timestamp-free synchronization for wireless body-area networks." In Consumer Communications and Networking Conference (CCNC), 2015 12th Annual IEEE, pp. 166-167. IEEE, 2015.

[10] Yan, Sen, Ping Jack Soh, and Guy AE Vandenbosch. "Wearable Dual-Band Magneto-Electric Dipole Antenna for WBAN/WLAN Applications." Antennas and Propagation, IEEE Transactions on 63, no. 9 (2015): 4165-4169.

[11] Harun Al Rasyid, M. Udin, Bih-Hwang Lee, and Amang Sudarsono. "Wireless body area network for monitoring body temperature, heart beat and oxygen in blood." In Intelligent Technology and Its Applications (ISITIA), 2015 International Seminar on, pp. 95-98. IEEE, 2015.

[12] Viittala, Harri, Matti Hamalainen, and Jari Iinatti. "Zonebased fuzzy routing for WBANs." In Medical Information and Communication Technology (ISMICT), 2015 9th International Symposium on, pp. 93-97. IEEE, 2015.

[13] Hamalainen, Matti, Tuomas Paso, Lorenzo Mucchi, Marc Girod-Genet, John Farserotu, Hirokazu Tanaka, Woon Hau Chin, and Lina Nachabe Ismail. "ETSI TC SmartBAN: Overview of the wireless body area network standard." In Medical Information and Communication Technology (ISMICT), 2015 9th International Symposium on, pp. 1-5. IEEE, 2015.
[14] Lahlou, Laaziz, Amira Meharouech, Jocelyne Elias, and Ahmed Mehaoua. "MAC-network cross-layer energy optimization model for Wireless Body Area Networks." In Protocol Engineering (ICPE) and International Conference on New Technologies of Distributed Systems (NTDS), 2015 International Conference on, pp. 1-5. IEEE, 2015

[15] ] Zang, Weilin, and Ye Li. "Motion aware transmission power control scheme in wireless body area network." In Signal Processing Systems (SiPS), 2015 IEEE Workshop on, pp. 1-5. IEEE, 2015.

[16] Sangari, A. Siva, and J. Martin Leo. "Polynomial based light weight security in wireless body area network." In Intelligent Systems and Control (ISCO), 2015 IEEE 9th International Conference on, pp. 1-5. IEEE, 2015.

[17] Ambigavathi, M., and D. Sridharan. "Priority based AODV routing protocol for critical data in Wireless Body Area Network." In Signal Processing, Communication and Networking (ICSCN), $20153 \mathrm{rd}$ International Conference on, pp. 1-5. IEEE, 2015.

[18] Le, Trong Nhan, Alain Pegatoquet, and Michele Magno. "Asynchronous on demand MAC protocol using wake-up radio in wireless body area network." In Advances in Sensors and Interfaces (IWASI), 2015 6th IEEE International Workshop on, pp. 228-233. IEEE, 2015.

[19] Pereira, António, Nelson Nunes, Daniel Vieira, Nuno Costa, Hugo Fernandes, and João Barroso. "Blind Guide: An Ultrasound Sensor-based Body Area Network for Guiding Blind People." Procedia Computer Science 67 (2015): 403-408

[20] Youssef, Soumaya Bel Hadj, Slim Rekhis, and Noureddine Boudriga. "Design and analysis of a WBANbased system for firefighters." In Wireless Communications and Mobile Computing Conference (IWCMC), 2015 International, pp. 526-531. IEEE, 2015.

[21] Wang, Hai, Bob Davies, and Abraham O. Fapojuwo. "Inter-wireless body area network scheduling algorithm for livestock health monitoring." In Wireless Communications and Networking Conference (WCNC), 2015 IEEE, pp. 2132-2137. IEEE, 2015.

[22] Gambhir, Sapna, Vrisha Tickoo, and Madhumita Kathuria. "Priority based congestion control in WBAN." In Contemporary Computing (IC3), 2015 Eighth International Conference on, pp. 428-433. IEEE, 2015.

[23] Chevalier, Ludovic, Stéphanie Sahuguede, and Anne Julien-Vergonjanne. "Wireless optical technology based body area network for health monitoring application." In Communications (ICC), 2015 IEEE International Conference on, pp. 2863-2868. IEEE, 2015.

[24] Pathak, Shashwat, Mayur Kumar, Amrita Mohan, and Basant Kumar. "Energy Optimization of ZigBee Based WBAN for Patient Monitoring." Procedia Computer Science 70 (2015): 414-420.

[25] Zhao, Zhenguo. "An efficient anonymous authentication scheme for wireless body area networks using elliptic curve cryptosystem." Journal of medical systems 38, no. 2 (2014): 1-7

[26] Ansari, Abdul Rahim, and Sunghyun Cho. "Human body: The future communication channel for WBAN." In 
Consumer Electronics (ISCE 2014), The 18th IEEE International Symposium on, pp. 1-3. IEEE, 2014.

[27] Sipal, Vit, Domenico Gaetano, Patrick McEvoy, and Max Ammann. "Impact of Hub Location on the Performance of Wireless Body Area Networks for Fitness Applications." (2014).
[28] Dautov, Ruslan, and Gill R. Tsouri. "Securing while Sampling in Wireless Body Area Networks with Application to Electrocardiography." (2014).

\section{APPENDIX}

\begin{tabular}{|c|c|c|c|c|c|}
\hline \multicolumn{6}{|c|}{ Table I } \\
\hline Sr No. & Title & $\begin{array}{c}\text { Author, } \\
\text { Publisher and } \\
\text { Year }\end{array}$ & $\begin{array}{l}\text { Working } \\
\text { Platform }\end{array}$ & Objective & Future Scope \\
\hline 1 & $\begin{array}{c}\text { A Dual-Band Printed Antenna } \\
\text { With Metal Back Cover For } \\
\text { Wban Applications }\end{array}$ & $\begin{array}{l}\text { Lee } \text { et.al [2] } \\
\text { IEEE [2015] }\end{array}$ & $\begin{array}{l}\text { A Dual-Band } \\
\text { Printed Antenna }\end{array}$ & WBAN Application & $\begin{array}{l}\text { Extend this work with varying } \\
\text { of various frequency bands. }\end{array}$ \\
\hline 2 & \begin{tabular}{|c|} 
An Effect Of Delay Reduced \\
Mac Protocol For Wban Based \\
Medical Signal Monitoring
\end{tabular} & $\begin{array}{l}\text { Kim et.al [5] } \\
\text { IEEE [2015] }\end{array}$ & MAC protocol & \begin{tabular}{|} 
DTD-MAC(Decrease of \\
Transmission Delay)
\end{tabular} & $\begin{array}{l}\text { It is necessary to derive the } \\
\text { improved approach to } \\
\text { guarantee the stable QoS in a } \\
\text { dynamic environment where } \\
\text { bio sensor nodes are added and } \\
\text { more tight performance } \\
\text { requirement. }\end{array}$ \\
\hline 3 & \begin{tabular}{|c|} 
Autonomous Mobile Agent \\
Based Intrusion \\
Detection Framework In \\
Wireless Body Area Networks
\end{tabular} & $\begin{array}{l}\text { Thamilarasu } \\
\text { et.al [1] } \\
\text { IEEE [2015] }\end{array}$ & $\begin{array}{l}\text { Mobile Agent } \\
\text { based }\end{array}$ & $\begin{array}{l}\text { Intrusion detection } \\
\text { Framework }\end{array}$ & $\begin{array}{l}\text { Implement proposed work for } \\
\text { WBAN. Check their feasibility } \\
\text { and suitability for WBAN. }\end{array}$ \\
\hline 4 & $\begin{array}{c}\text { Flexible Antenna For Wireless } \\
\text { Body Area Network }\end{array}$ & $\begin{array}{l}\text { Froehle } \text { et.al [6] } \\
\text { IEEE [2015] }\end{array}$ & Flexible Antenna & $\begin{array}{c}\text { Next generation } \\
\text { spacesuit } 2(\mathrm{NDX}-2) .\end{array}$ & $\begin{array}{l}\text { Decrease the air gap between } \\
\text { the substrate and ground plane. }\end{array}$ \\
\hline 5 & $\begin{array}{c}\text { Multi-Hop Wban Construction } \\
\text { For Healthcare Iot } \\
\text { Systems }\end{array}$ & $\begin{array}{l}\text { Kim et.al [7] } \\
\text { IEEE [2015] }\end{array}$ & Multi hop network & $\begin{array}{l}\text { Health care IoT } \\
\text { Systems }\end{array}$ & $\begin{array}{l}\text { Extend this work for other } \\
\text { WBAN Application. }\end{array}$ \\
\hline 6 & $\begin{array}{c}\text { Performance Analysis Of } \\
\text { Wban Based On } \\
\text { Aodv And Dsdv Routing } \\
\text { Protocols* }\end{array}$ & $\begin{array}{l}\text { He et.al [8] } \\
\text { IEEE[2015] }\end{array}$ & $\begin{array}{l}\text { AODV \& DSDV } \\
\text { Protocols }\end{array}$ & $\begin{array}{c}\text { Body topology model of } \\
\text { WBAN }\end{array}$ & $\begin{array}{l}\text { Focus on routing protocols } \\
\text { performance analysis for } \\
\text { different QoS health } \\
\text { information. }\end{array}$ \\
\hline 7 & $\begin{array}{c}\text { Timestamp-Free } \\
\text { Synchronization For Wireless } \\
\text { Bodyarea Networks }\end{array}$ & $\begin{array}{l}\text { Ramlall et.al } \\
\text { [9] } \\
\text { IEEE [2015] }\end{array}$ & $\begin{array}{c}\text { Power constrained } \\
\text { network }\end{array}$ & $\begin{array}{l}\text { Timestamp-free } \\
\text { synchronization } \\
\text { algorithm }\end{array}$ & $\begin{array}{l}\text { Extend this work for other } \\
\text { WBAN unsolved issues. }\end{array}$ \\
\hline 8 & $\begin{array}{c}\text { Wearable Dual-Band } \\
\text { Magneto-Electric Dipole } \\
\text { Antenna For Wban/Wlan } \\
\text { Applications }\end{array}$ & $\begin{array}{l}\text { Yan et.al [10] } \\
\text { IEEE [2015] }\end{array}$ & $\begin{array}{l}\text { Magneto-Electric } \\
\text { Dipole } \\
\text { Antenna topology }\end{array}$ & $\begin{array}{c}\text { WBAN and } \\
\text { WLAN applications. }\end{array}$ & $\begin{array}{l}\text { Extend the work and try above } \\
\text { the European limit of } 2 \mathrm{~W} / \mathrm{kg} \text {. }\end{array}$ \\
\hline 9 & $\begin{array}{l}\text { Wireless Body Area Network } \\
\text { For Monitoring Body } \\
\text { Temperature, Heart Beat And } \\
\text { Oxygen In Blood }\end{array}$ & $\begin{array}{c}\text { A1 Rasyid et.al } \\
{[11]} \\
\text { IEEE [2015] }\end{array}$ & ZigBee Network & $\begin{array}{c}\text { Monitoring Body } \\
\text { Temperature, Heart } \\
\text { Beat And Oxygen In } \\
\text { Blood }\end{array}$ & $\begin{array}{l}\text { Develop real time visualization } \\
\text { monitoring application in } \\
\text { desktop-based and web-based } \\
\text { to get sensitive data. }\end{array}$ \\
\hline 10 & $\begin{array}{c}\text { Zone-Based Fuzzy Routing } \\
\text { For Wbans }\end{array}$ & $\begin{array}{l}\text { Viittala et.al } \\
\quad[12]\end{array}$ & $\begin{array}{l}\text { Zone routing } \\
\text { protocol (ZRP) }\end{array}$ & Fuzzy logic & $\begin{array}{l}\text { Focus on detailing membership } \\
\text { functions for FLC and }\end{array}$ \\
\hline
\end{tabular}




\begin{tabular}{|c|c|c|c|c|c|}
\hline & & IEEE [2015] & & & $\begin{array}{l}\text { analyzing and simulating the } \\
\text { performance of the protocol. }\end{array}$ \\
\hline 11 & Etsi Tc Smartban & $\begin{array}{l}\text { Hämäläinen } \\
\text { et.al [13] } \\
\text { IEEE [2015] }\end{array}$ & $\begin{array}{c}\text { PHY and MAC } \\
\text { layers }\end{array}$ & SmartBAN & $\begin{array}{l}\text { Wearable or implantable } \\
\text { SmartBAN devices are } \\
\text { expected to operate more } \\
\text { frequently in specific types of } \\
\text { environment. }\end{array}$ \\
\hline 12 & $\begin{array}{l}\text { Mac-Network Cross-Layer } \\
\text { Energy Optimization } \\
\text { Model For Wireless Body } \\
\text { Area Networks }\end{array}$ & $\begin{array}{l}\text { Lahlou† et.al } \\
\qquad[14] \\
\text { IEEE [2015] }\end{array}$ & MAC layer & $\begin{array}{c}\text { Energy-Aware } \\
\text { Topology Design for } \\
\text { WBANs (EAWD) } \\
\& \text { Enhanced EAWD } \\
\text { (EEAWD) }\end{array}$ & $\begin{array}{l}\text { To implement and validate } \\
\text { EEAWD through simulations } \\
\text { or experiments. }\end{array}$ \\
\hline 13 & $\begin{array}{c}\text { Motion Aware Transmission } \\
\text { Power Control Scheme In } \\
\text { Wireless Body Area Network }\end{array}$ & $\begin{array}{l}\text { Zang et.al [15] } \\
\text { IEEE [2015] }\end{array}$ & ZigBee platform & $\begin{array}{l}\text { Transmission power } \\
\text { control scheme (TPC) } \\
\text { \& Motion aware } \\
\text { transmission power } \\
\text { control (M-TPC) }\end{array}$ & $\begin{array}{l}\text { Improve the Packet delivery } \\
\text { latency. }\end{array}$ \\
\hline 14 & $\begin{array}{c}\text { Polynomial Based Light } \\
\text { Weight Security In Wireless } \\
\text { Body Area Network }\end{array}$ & $\begin{array}{l}\text { Sangari et.al } \\
\quad[16] \\
\text { IEEE [2015] }\end{array}$ & ZigBee technology & Telemedicine system & $\begin{array}{l}\text { Try to improve remote elder } \\
\text { people monitoring and provide } \\
\text { alertness through } 3 \mathrm{G} \\
\text { communications. Improving } \\
\text { scalability and improve power } \\
\text { management for long term use. }\end{array}$ \\
\hline 15 & $\begin{array}{l}\text { Priority Based Aodv Routing } \\
\text { Protocol/Or Critical Data In } \\
\text { Wireless Body Area Network }\end{array}$ & $\begin{array}{l}\text { Ambigavathi } \\
\text { et.al [17] } \\
\text { IEEE [2015] }\end{array}$ & $\begin{array}{l}\text { AODV routing } \\
\text { protocol }\end{array}$ & $\begin{array}{l}\text { Priority Queuing } \\
\text { Algorithm }\end{array}$ & $\begin{array}{l}\text { Try with any other routing } \\
\text { protocol to check the delivery } \\
\text { time of critical data. }\end{array}$ \\
\hline 16 & $\begin{array}{l}\text { Asynchronous On Demand } \\
\text { Mac Protocol Using } \\
\text { Wake-Up Radio In Wireless } \\
\text { Body Area Network }\end{array}$ & $\begin{array}{l}\text { Nhan Le et.al } \\
\quad[18] \\
\text { IEEE [2015] }\end{array}$ & MAC Protocol & $\begin{array}{l}\text { ASYNCHRONOUS } \\
\text { WAKE-UP ON } \\
\text { DEMAND MAC } \\
\text { PROTOCOL (AWD- } \\
\text { MAC) }\end{array}$ & $\begin{array}{l}\text { Evaluate the false positive } \\
\text { influence of the WUR and the } \\
\text { effects of the latency due to the } \\
\text { WUR addressing capability. }\end{array}$ \\
\hline 17 & $\begin{array}{l}\text { Blind Guide: An Ultrasound } \\
\text { Sensor-Based Body Area } \\
\text { Network For Guiding Blind } \\
\text { People }\end{array}$ & $\begin{array}{l}\text { Pereira et.al } \\
\quad[19] \\
\\
\text { ELSEVIER } \\
\text { [2015] }\end{array}$ & Ultrasound sensor & $\begin{array}{l}\text { Blind guide for Blind } \\
\text { people }\end{array}$ & $\begin{array}{l}\text { Replace the Mica2 and } \\
\text { Mica2Dot sensor nodes by } \\
\text { plastic printed circuits. }\end{array}$ \\
\hline 18 & $\begin{array}{c}\text { Design And Analysis Of A } \\
\text { Wban-Based System For } \\
\text { Firefighters }\end{array}$ & $\begin{array}{l}\text { Youssef et.al } \\
\quad[20] \\
\text { IEEE [2015] }\end{array}$ & $\begin{array}{l}\text { cluster-based } \\
\text { hierarchical } \\
\text { topology }\end{array}$ & $\begin{array}{l}\text { Firefighter scheme for } \\
\text { Firefighters }\end{array}$ & $\begin{array}{l}\text { Implement this firefighting } \\
\text { system in real life for } \\
\text { firefighters. }\end{array}$ \\
\hline 19 & $\begin{array}{l}\text { Inter-Wireless Body Area } \\
\text { Network Scheduling } \\
\text { Algorithm For Livestock } \\
\text { Health Monitoring }\end{array}$ & $\begin{array}{l}\text { Wang et.al [21] } \\
\text { IEEE [2015] }\end{array}$ & Wireless medium & $\begin{array}{c}\text { Inter-wireless body area } \\
\text { network scheduling } \\
\text { algorithm for animal } \\
\text { health monitoring }\end{array}$ & $\begin{array}{l}\text { Implement this algorithm in } \\
\text { real life for animal health } \\
\text { monitoring system. }\end{array}$ \\
\hline 20 & $\begin{array}{l}\text { Priority Based Congestion } \\
\text { Control In Wban }\end{array}$ & $\begin{array}{l}\text { Gambhir et.al } \\
\qquad[22] \\
\text { IEEE [2015] }\end{array}$ & Transport layer & For reduce Congestion & $\begin{array}{l}\text { Congestion should be detected } \\
\text { using other factors like } \\
\text { bandwidth, network delay. }\end{array}$ \\
\hline 21 & \begin{tabular}{|c|} 
Wireless Optical Technology \\
Based Body Area Network For
\end{tabular} & $\begin{array}{c}\text { Chevalier } \text { et.al } \\
{[23]}\end{array}$ & $\begin{array}{l}\text { Wireless Optical } \\
\text { technology }\end{array}$ & $\begin{array}{l}\text { Health Monitoring } \\
\text { Application }\end{array}$ & $\begin{array}{l}\text { Try with more On-body sensor } \\
\text { for measure more accurate }\end{array}$ \\
\hline
\end{tabular}




\begin{tabular}{|c|c|c|c|c|c|}
\hline & Health Monitoring Application & IEEE [2015] & & & result. \\
\hline 22 & $\begin{array}{c}\text { Energy Optimization Of } \\
\text { Zigbee Based Wban For } \\
\text { Patient } \\
\text { Monitoring }\end{array}$ & $\begin{array}{l}\text { Pathak et.al } \\
\qquad[24] \\
\text { ELSEVIER } \\
\text { [2015] }\end{array}$ & ZigBee network & Patient Monitoring & $\begin{array}{l}\text { Try this scheme for other } \\
\text { telemedicine application and } \\
\text { compare their result with this. }\end{array}$ \\
\hline 23 & $\begin{array}{l}\text { An Efficient Anonymous } \\
\text { Authentication Scheme For } \\
\quad \text { Wireless } \\
\text { Body Area Networks Using } \\
\text { Elliptic Curve Cryptosystem }\end{array}$ & \begin{tabular}{|l} 
Zhao et.al [25] \\
Springer [2014]
\end{tabular} & $\begin{array}{l}\text { secure sockets } \\
\text { layer (SSL) } \\
\text { protocol }\end{array}$ & $\begin{array}{l}\text { Elliptic Curve } \\
\text { Cryptosystem }\end{array}$ & $\begin{array}{l}\text { Try with other cryptosystem } \\
\text { and compare with this system. }\end{array}$ \\
\hline 24 & $\begin{array}{c}\text { Forensics Readiness For } \\
\text { Wireless Body Area Network } \\
\text { (Wban) System }\end{array}$ & $\begin{array}{l}\text { Rahman et.al } \\
\text { [3] } \\
\text { IEEE [2014] }\end{array}$ & $\begin{array}{l}\text { Forensics } \\
\text { Readiness }\end{array}$ & $\begin{array}{l}\text { Practical Impact } \\
\text { Assessment (PIA) }\end{array}$ & $\begin{array}{l}\text { Implement current research as } \\
\text { practically and prove it. }\end{array}$ \\
\hline 25 & $\begin{array}{l}\text { Human Body: The Future } \\
\text { Communication Channel } \\
\text { For Wban }\end{array}$ & $\begin{array}{l}\text { Ansari et.al } \\
\qquad[26] \\
\text { IEEE [2014] }\end{array}$ & $\begin{array}{l}\text { Communication } \\
\text { Channel }\end{array}$ & $\begin{array}{c}\text { Human body } \\
\text { communication (HBC) }\end{array}$ & $\begin{array}{c}\text { Practically take the result of RF } \\
\text { and non-RF techniques. }\end{array}$ \\
\hline 26 & $\begin{array}{c}\text { Impact Of Hub Location On } \\
\text { The Performance Of } \\
\text { Wireless Body Area Networks } \\
\text { For Fitness } \\
\text { Applications }\end{array}$ & \begin{tabular}{|c|} 
Sipal et.al [27] \\
IEEE[2014]
\end{tabular} & Hub Location & Fitness Application & $\begin{array}{l}\text { Focus on the expanding the } \\
\text { study for off-body networks to } \\
\text { explore the impact of the hub } \\
\text { location on off-body links. }\end{array}$ \\
\hline 27 & $\begin{array}{c}\text { Securing While Sampling In } \\
\text { Wireless Body Area } \\
\text { Networks With Application To } \\
\text { Electrocardiography }\end{array}$ & $\begin{array}{l}\text { Dautov et.al } \\
\quad[28] \\
\text { IEEE [2014] }\end{array}$ & Physical layer & $\begin{array}{l}\text { Electrocardiography } \\
\text { Application }\end{array}$ & $\begin{array}{l}\text { Apply Compressed Sensing for } \\
\text { other bio medical application } \\
\text { and Evaluate their } \\
\text { performance. }\end{array}$ \\
\hline
\end{tabular}

